M. Anderson, F. Bridier, J. Gholipour, M. Jahazi, P. Wanjara, P. Bocher, J. Savoie

"Mechanical and Metallurgical Evolution of Stainless Steel 321 in a Multi-step Forming Process"

Journal of Materials Engineering and Performance 25(4), pp. 1526-1538

https://doi.org/10.1007/s11665-016-1928-4

Copyright 2016 ASM International. This paper was published in Journal of Materials Engineering and Performance, Vol. 25, Issue 4, pp. 1526-1538 and is made available as an electronic reprint with the permission of ASM International. One print or electronic copy may be made for personal use only. Systematic or multiple reproduction distribution to multiple locations via electronic or other means, duplications of any material in this paper for a fee or for commercial purposes, or modification of the content of this paper are prohibited. 


\title{
Mechanical and Metallurgical Evolution of Stainless Steel 321 in a Multi-step Forming Process
}

\author{
M. Anderson, F. Bridier, J. Gholipour, M. Jahazi, P. Wanjara, P. Bocher, and J. Savoie
}

\author{
(Submitted December 1, 2015; in revised form January 19, 2016; published online February 5, 2016)
}

\begin{abstract}
This paper examines the metallurgical evolution of AISI Stainless Steel 321 (SS 321) during multi-step forming, a process that involves cycles of deformation with intermediate heat treatment steps. The multistep forming process was simulated by implementing interrupted uniaxial tensile testing experiments. Evolution of the mechanical properties as well as the microstructural features, such as twins and textures of the austenite and martensite phases, was studied as a function of the multi-step forming process. The characteristics of the Strain-Induced Martensite (SIM) were also documented for each deformation step and intermediate stress relief heat treatment. The results indicated that the intermediate heat treatments considerably increased the formability of SS 321. Texture analysis showed that the effect of the intermediate heat treatment on the austenite was minor and led to partial recrystallization, while deformation was observed to reinforce the crystallographic texture of austenite. For the SIM, an Olson-Cohen equation type was identified to analytically predict its formation during the multi-step forming process. The generated SIM was textured and weakened with increasing deformation.
\end{abstract}

Keywords crystallographic texture, multi-step forming, stainless steel, strain-induced martensite, tensile test

\section{Introduction}

Austenitic stainless steels are widely used for engineering applications due to their high strength combined with relatively good formability. Type 321 is an austenitic chromium-nickel stainless steel (SS) stabilized with a titanium addition of at least five times the carbon content. Manufacturing of SS 321 typically involves multiple processing steps to attain the geometric dimensions, microstructure, and mechanical properties required of the part. Consequently, the possibility of increasing the formability of SS 321 through multi-step forming is of specific interest for a wide range of applications in the aerospace, automotive, and power generation industries. This process is important for the manufacturing of complex parts requiring medium to high strain levels, such as in hydroforming.

In multi-step forming, the combination of plastic deformation and heat treatment raises the question of recrystallization occurrence. As with most Face-Centered Cubic (FCC) metals with low Stacking Fault Energy (SFE), SS 321 is prone to the

M. Anderson, Mechanical Engineering Department, Ecole de Technologie Superieure, Montreal, Canada and Aerospace, Structures, Materials and Manufacturing, National Research Council Canada, Montreal, Canada; F. Bridier, Mechanical Engineering Department, Ecole de Technologie Superieure, Montreal, Canada and DCNS Research, DCNS, Nantes-Indret, France; J. Gholipour and P. Wanjara, Aerospace, Structures, Materials and Manufacturing, National Research Council Canada, Montreal, Canada; M. Jahazi and P. Bocher, Mechanical Engineering Department, Ecole de Technologie Superieure, Montreal, Canada; and J. Savoie, Special Process Development Group, Pratt \& Whitney Canada, Longueuil, Canada. Contact e-mails: philippe.bocher@etsmtl.ca and melissa.anderson.1@ens.etsmtl.ca.

formation of annealing twins that when present in the microstructure indicate that the alloy underwent sufficient mechanical deformation prior to heat treatment to induce recrystallization. Several mechanisms leading to the formation of annealing twins have been suggested (Ref 1-4), and, reasonably, they most likely result from accidents associated with the growth of recrystallized grains originating in a previously deformed material that possesses a high density of stacking faults (Ref 5). Thus, analyzing the amount of annealing twins at different stages in the multi-step forming process may provide evidence for the possible occurrence of recrystallization.

Considering that the trend for 300-series Fe-Cr-Ni stainless steels shows suppression of the martensitic transformation temperature and, in turn the Strain Induce Martensite (SIM) with increasing nickel and chromium concentrations, the relatively low amount of nickel in SS 321 is thus expected to facilitate a phase transformation from austenite to martensite during plastic deformation. This SIM tends to enhance work hardening and may significantly modify the mechanical behavior of the material. SIM transformation is well documented, particularly for metastable austenitic stainless steels with low SFE, such as SS304 or SS316 (Ref 6-10). The relationship between SIM formation and formability improvement of the alloy is known to be a very complex phenomenon. In fact, in the case of uniaxial tension, the ductility appears to depend on both the extent of martensite formation and the strain at which martensite starts to form (Ref 11, 12). It is then important to precisely document the evolution of SIM with the applied strain.

In the case of SS 321, only a few authors have reported on this phenomenon (Ref 13-15). Also the transformation from austenite to martensite as a result of plastic strain was enhanced by low strain rates, low temperatures, and lower nickel contents (Ref 11, 16, 17). Moreover, the martensite phase was reported to appear heterogeneously in certain austenitic grains after intense cold working ( $\operatorname{Ref} 10,18)$. It is noteworthy that there are actually two types of martensite formed sequentially: 
austenite $\quad \gamma(\mathrm{FCC}) \rightarrow$ martensite $\quad \varepsilon(\mathrm{HCP}) \rightarrow$ martensite $\alpha^{\prime}(\mathrm{BCC})$, where the terms $\mathrm{HCP}$ and $\mathrm{BCC}$ refer to the Hexagonal Closed Packed and Body-Centered Cubic crystal structures (Ref $6,19,20)$. The volume percent of $\varepsilon$-martensite compared to that of $\alpha^{\prime}$-martensite is considered negligible above approximately $15 \%$ strain (Ref 21,22$)$.

In order to predict the amount of martensite generated during deformation, several equations relating the volume fraction of martensite and the plastic strain have been developed. The progress observed has been summarized by Peterson (Ref 23). Specifically, Angel (Ref 11) and then Olson and Cohen (Ref 24) developed a model for the kinetics of SIM nucleation based on a shear-band intersection mechanism. This model has been recently applied by Talonen et al. (Ref 20) on SS304 and SS301LN. On the other hand, Ramirez (Ref 25) and Tsuta (Ref 26) suggested an alternative model, also resulting from the Olson and Cohen equation, that described the kinetics of $\alpha$-martensite transformation for a material subjected to complex strain paths. Grosse (Ref 13) used the latter model in his study of martensite transformation during low cycle fatigue for SS 321 and adapted it for low volume fractions of martensite (less than $30 \%$ ). In the present study, both models (Olson-Cohen and Tsuta-Grosse) were implemented to describe the SIM measurements as a function of the cumulative strain because no parameters in these models are currently available for the case of a multi-step forming process:

The Olson-Cohen equation is as follows:

$X_{M}=1-\exp \left[-\beta[1-\exp (-\alpha \times \varepsilon)]^{n}\right]$

where $X_{M}$ is the $\alpha^{\prime}$-martensite volume fraction, $\alpha$ and $\beta$ are temperature-dependent constants, $\mathrm{n}$ is a fixed exponent evaluated at 4.5 for austenitic stainless steels (Ref 24), and $\varepsilon$ is the true strain. The $\alpha$ parameter describes how fast shear bands form with strain and depends on the SFE. The $\beta$ parameter is proportional to the probability that a shear band intersection generates a $\alpha^{\prime}$-martensite embryo: this parameter is strongly related to the chemical driving force of the alloy.

Tsuta-Grosse equation is developed as follows:

$X_{M}=A \times \varepsilon^{B} \times \exp \left(-B Q_{T}\right)$

where $\mathrm{A}$ and $\mathrm{B}$ are parameters that depend on the material conditions, Q is the activation energy for initiating the reaction, and $\mathrm{T}$ is the temperature.

The crystallographic orientation relationship between austenite and SIM after cold rolling has been widely studied and was found to be of the Kurdjumov-Sachs (K-S) type (Ref 27-29). This implies that the formed $\{110\}$ martensite plane is parallel to the parent $\{111\}$ austenite plane and the [111] martensite direction is parallel to the [101] direction of the austenite (Ref 30, 31]. Texture evolution in austenitic stainless steels during uniaxial tensile deformation was studied by some authors who reported that two strong fiber textures belonging to the $\langle 111\rangle$ and $\langle 100\rangle$ directions parallel to the tensile direction were formed (Ref 32, 33). However, the texture evolution of both austenite and the generated martensite developed during deformation of SS 321 has not been reported, especially in the case where intermediate heat treatments are introduced between the deformation steps. Hence, the purpose of the present work is to observe the changes in the mechanical properties and metallurgical characteristics of the material when multi-step forming is conducted, giving the opportunity to document the associated SIM in the alloy subjected to this specific process.

\section{Experimental Procedure}

\subsection{Material}

The composition, in weight percent (wt.\%), of the 0.9-mmthick austenitic SS 321 sheet material used is given in Table 1. The microstructure of the as-received sheet is presented in Fig. 1. The average equiaxed austenitic grain size is about $8 \mu \mathrm{m}$. All specimens were subjected to a stress relief heat treatment $\left(982{ }^{\circ} \mathrm{C}\right.$ for $\left.1 \mathrm{~h}\right)$ prior to testing to ensure that the initial material conditions were similar.

\subsection{Mechanical Tests}

To emulate a multi-step forming process, tensile tests were conducted at room temperature with a Kammrath\&Weiss ${ }^{\circledR}$ micro testing machine using flat micro-tensile specimens with a 15 -mm gauge length and $4 \mathrm{~mm}$ width. It is noteworthy that all specimens were manufactured with Electro Discharge Machining (EDM). The strain was applied in the Rolling Direction (RD) of the sheet and measured with a mechanical extensometer that had a maximum displacement range of $1 \mathrm{~mm}$. By contrast, the load data were collected through a microprocessor interfaced with the acquisition recording system of the tensile testing machine. Tensile loading was performed under displacement control mode with a strain rate of $0.03 \mathrm{~s}^{-1}$ up to a limit strain of $40 \%$. Due to the limitation of the micro-tensile testing machine in terms of the stroke, a total cumulative strain of $100 \%$ was delimited for the experiments. In order to study

Table 1 Chemical composition of the as-received SS 321 sheet

\begin{tabular}{lccccccccc}
\hline Element & $\mathbf{F e}$ & $\mathbf{N i}$ & $\mathbf{C r}$ & $\mathbf{S i}$ & $\mathbf{A l}$ & $\mathbf{T i}$ & $\mathbf{M n}$ & $\mathbf{S}$ & $\mathbf{P}$ \\
\hline wt.\% & 67.60 & 8.50 & 16.63 & 0.38 & 0.05 & 0.20 & 1.30 & 0.10 & 0.001 \\
\hline
\end{tabular}

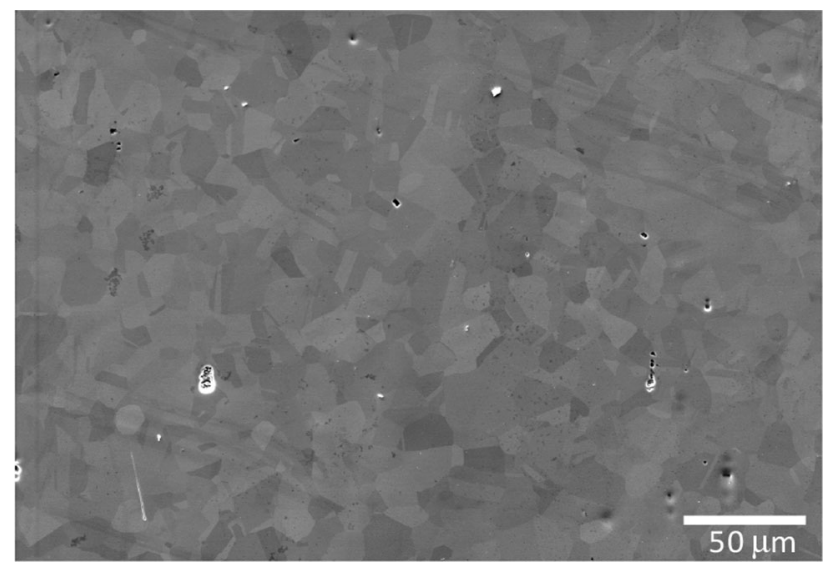

Fig. 1 SEM image (SE mode) of SS 321 in the as-received condition 
the strain-induced martensite evolution, the tensile tests were interrupted at specific strain levels to allow measurements at each stage. Thereafter, tensile loading was then continued up to the limit strain of $40 \%$, at which point a heat treatment step was undertaken. Figure 2 shows the set-up of the tensile tests.

\subsection{Heat Treatments}

The initial and intermediate heat treatment consisted of holding the specimen for $1 \mathrm{~h}$ under a secondary vacuum at $982{ }^{\circ} \mathrm{C}$ followed by rapid cooling at a rate $\geq 19{ }^{\circ} \mathrm{C} / \mathrm{min}$ to prevent chromium carbide formation, which may cause sensitization in SS 321 (Ref 34). Considering that SS 321 can only be hardened by cold working, the heat treatment conducted was a stress relief(SR) to provide annealing of the material (static recovery and/or recrystallization). This results in a significant reduction in the yield stress with a concomitant increase in the ductility.

\subsection{Interrupted Thermo-mechanical Testing}

Table 2 describes the experimental design of the interrupted thermo-mechanical tests. As mentioned, each specimen was subjected to an initial SR heat treatment. It is important to mention that the generic term "strain" in this paper refers to the engineering strain. To support documenting the deformation evolution, a set of four specimens was deformed to $25 \%$ strain (i.e., step 0) without any subsequent SR heat treatment. For the interrupted thermo-mechanical tests, the tensile tests were pursued up to the limit strain of $40 \%$ (Step 1). The SR heat treatment was performed (Step 1-SR) before the next cycle of tensile loading up to the limit strain of $40 \%$ (Step 2) with a SR heat treatment performed (Step 2-SR) and finally the last

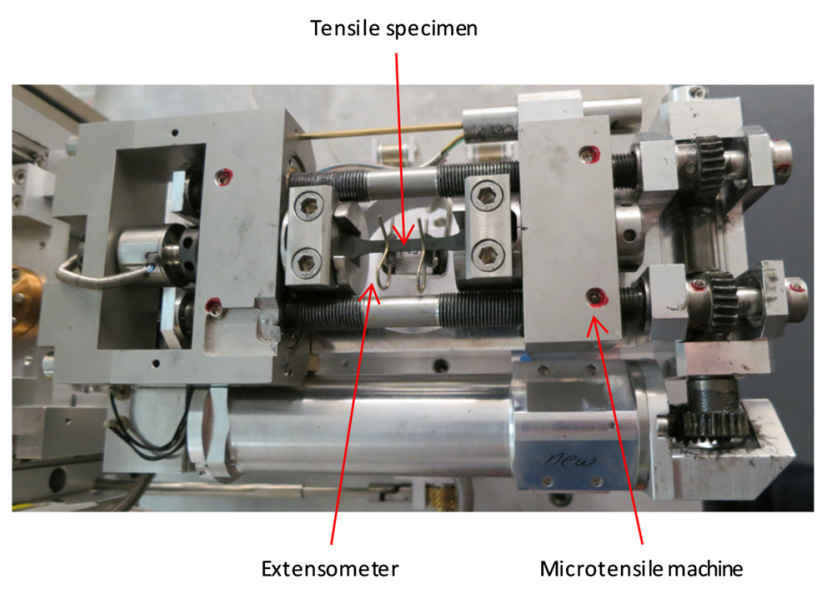

Fig. 2 Set-up for the uniaxial micro-tensile test loading step up to $20 \%$ (Step 3) was applied. It is noteworthy that the limit strain value of $40 \%$ was selected to be close to but less than that for the onset of necking (Ref 35). The methodology applied for the tests involved starting with four identical specimens and then retaining one sample after each deformation step for metallurgical analysis. Thus, the first sequence of the process (step 1: SR $+40 \%$ ) was performed on four samples, then the second step (step 2: step $1+\mathrm{SR}+40 \%$ ) on 3 samples, and finally the last step (step 3: step $2+\mathrm{SR}+20 \%$ ) on 2 samples. Final tensile loading was performed up to $20 \%$ strain to reach a total cumulative strain of $100 \%$.

\subsection{Microstructure and Texture Analysis}

To examine the microstructure, metallographic preparation was performed using automated grinding and polishing techniques, followed by vibratory polishing (Vibro-Met) with colloidal silica for $12 \mathrm{~h}$ to render surfaces suitable for Electron BackScatter Diffraction (EBSD). The microstructures were examined in the central region of the gauge length of the tensile specimen obtained from each step in the interrupted thermomechanical process, using a high-resolution Hitachi SU-70 Field Emission Gun-Scanning Electron Microscope (FEGSEM) equipped with an Oxford-Channel 5 HKL EBSD acquisition and analysis system. The FEG-SEM was operated at $20 \mathrm{kV}$ with a probe current of $14 \mathrm{nA}$. Two different types of EBSD maps were acquired. The first one was performed over a relatively large area of $1905 \times 1425 \mu^{2}$ with a step size of $1 \mu \mathrm{m}$ to cover a sufficient number of grains for statistical calculations (grain size distribution, fraction of twins, etc.) of the austenitic grains. A minimum of 2000 grains were sampled in these larger maps. The annealing twins were defined in the Channel 5 software as having a misorientation of $60^{\circ}$ along the $\langle 111\rangle$ axis with a maximum deviation of $5^{\circ}$. The amount of twins corresponded to the linear percentage of special boundaries $\left(60^{\circ}\langle 111\rangle\right)$ in relation to the overall length of boundaries. Grain size distribution analyses were performed based on the EBSD maps following the ASTM E2627-13 standard. The grains were reconstructed using a critical misorientation angle of $15^{\circ}$ between adjacent pixels, and all grains with an area smaller than 8 pixels were considered as noise and removed before the data evaluation. In order to reveal the subgrain structure, grain boundaries and subgrain boundaries were plotted as black lines: an arbitrary deviation of $5^{\circ}$ was used as subgrain criterion. The grain size distributions were presented by cumulative plots. A second type of EBSD map was recorded over an area of $635 \times 475 \mu \mathrm{m}^{2}$ with a step size of $0.25 \mu \mathrm{m}$ to study both the austenite and martensite textures. The austenite texture resulting from both maps (large and small areas), when compared, was identical. In other words, the

Table 2 Design of experiments for the interrupted tensile tests

\begin{tabular}{llccc}
\hline \multicolumn{1}{c}{ Condition } & Number of samples & Cumulative engineering strain & Intermediate heat treatments \\
\hline Start & SR & 4 & $\ldots$ & $\ldots$ \\
Step 0 & SR $+25 \%$ & 4 & $25 \%$ & $\ldots$ \\
Step 1 & SR $+40 \%$ & 4 & $40 \%$ & $\ldots$ \\
Step 1-SR & SR $+40 \%+$ SR & 3 & $40 \%$ & $1 \mathrm{x}$ \\
Step 2 & SR $+40 \%+$ SR $+40 \%$ & 3 & $80 \%$ & $1 \mathrm{x}$ \\
Step 2-SR & SR $+40 \%+$ SR $+40 \%+$ SR & 2 & $80 \%$ & $2 \mathrm{x}$ \\
Step 3 & SR $+40 \%+$ SR $+40 \%+$ SR $+20 \%$ & 2 & $100 \%$ & $2 \mathrm{x}$ \\
\hline
\end{tabular}


findings obtained in the small section of the sample were representative of the global texture. The pole figures reported in this work correspond to $\{100\}$ and $\{111\}$ planes of the austenite phase and the $\{100\}$ and $\{110\}$ planes of the straininduced martensite.

\subsection{Measurement of the a'-Martensite Content}

The $\alpha$ '-martensite content was measured using a Feritscope ${ }^{\circledR}$ (Model MP3C, Helmut Fisher $\mathrm{GmbH}$ ), a non-destructive inspection (NDI) device based on a magnetic induction method that was originally designed to measure the $\delta$-ferrite content in austenitic stainless steel welds. However, since all magnetisable structures are measureable with the Feritscope ${ }^{\circledR}$ instrument, ferromagnetic $\alpha$-martensite can be differentiated from paramagnetic austenite in SS 321. In this magneto-inductive test methodology, an electromagnetic field generated by a coil interacts with the magnetic constituents in the specimen, namely martensite in SS 321. The magnetization of the martensite phase induces an electrical potential difference in the second coil and this output voltage is linearly related to the magnetic permeability of the specimen, which can then be related to the martensite content through the rule of mixtures (Ref 36, 37). It has been reported that this method is a direct and reliable way to quantify low amounts (e.g., between $0.1 \%$ and $40 \%$ ) of $\alpha$-martensite (Ref 20,38). To obtain a quantitative measure of the $\alpha$-martensite volume fraction from its magnetic permeability, Talonen et al. (Ref 38). converted the measured voltage (Feritscope readings) to an actual $\alpha$ '-martensite content

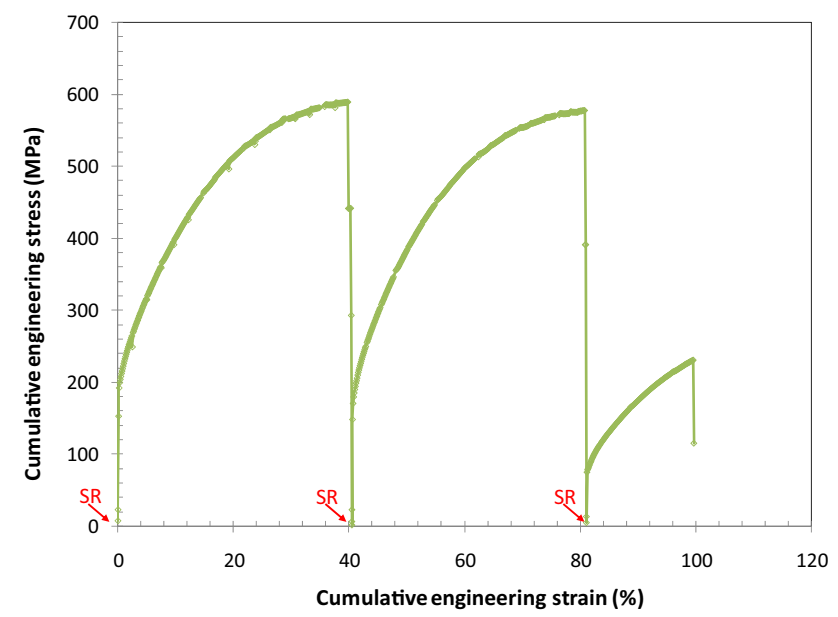

Fig. 3 Average cumulative stress-strain curve for specimens subjected to interrupted tensile testing to simulate multi-step forming. (Arrows show the SR heat treatment steps) in austenitic stainless steel using the following calibration equation:

$\alpha^{\prime}$ - martensite content $=1.71 \times$ Feritscope reading.

In the present work, five Feritscope readings (output voltage) were measured on the surface of each tensile specimen along the gauge length; the readings were then converted (using Eq 3) to actual $\alpha$ '-martensite contents. The minimum, maximum, and average values of the $\alpha$ '-martensite content are reported for each tensile specimen.

\section{Results}

\subsection{Mechanical Properties}

3.1.1 Cumulative Stress-Strain Curves. The average cumulative engineering stress-strain curve, obtained from the interrupted tensile tests, is presented in Fig. 3. The specimens that were cycled-pulled to the $40 \%$ limit strain, unloaded, and subjected to the SR heat treatment-twice before finally being reloaded to a strain of $20 \%$, gave a total cumulative engineering strain of $100 \%$. The cumulative strain was calculated by considering the "altered" dimensions of the specimen after each deformation step as input values. The mechanical properties, i.e., the conventional $0.2 \%$ yield strength (YS) and the maximum strength reached at the limit strain (i.e., limit stress) of the specimens at each step of the process are listed in Table 3. It is important to note that it was a challenge to experimentally determine a value for the Young's modulus (E) due to the limited elastic range of SS 321 and the equipment constraints that limited the number of data acquisition points obtained in this region of the stress-strain curves. As a consequence, the obtained results were not found to be reliable and, as such, were not used. Instead, the YS was calculated based on the Young's modulus of SS 321 $(184.5 \mathrm{GPa})$ that was measured previously by the current authors from tensile curves of macroscopic samples (Ref 39).

Examining the stress-strain curves in Fig. 3, it is evident that tensile loading at each step resulted in a similar mechanical response, though a clear drop in the YS is obvious from the data presented in Table 3. The same level of deformation was reached without early necking, confirming that the SR heat treatment sufficiently restored the formability of material. The YS decreased with the number of heat treatment cycles. After the first loading and SR heat treatment cycle, the YS decreased by $3 \%$ (from $\sim 193$ to $\sim 187 \mathrm{MPa}$ ). When, an additional loading and SR heat treatment cycle was performed, the YS reduced by $16 \%$ (from $\sim 187$ to $\sim 157 \mathrm{MPa}$ ), such that the overall decrease in the YS was $19 \%$ at $100 \%$ cumulative strain. This decrease in

Table 3 Mechanical properties of specimens subjected to interrupted tensile testing

\begin{tabular}{|c|c|c|c|c|c|c|}
\hline \multirow[b]{2}{*}{ Properties } & \multicolumn{2}{|c|}{ Step 1 (40\% limit strain) } & \multicolumn{2}{|c|}{ Step $2(40 \%$ limit strain $)$} & \multicolumn{2}{|c|}{ Step $3(20 \%$ limit strain $)$} \\
\hline & Average (4) & $\mathrm{SE}^{*}$ & Average (3) & SE* & Average (2) & SE* \\
\hline YS, MPa & 193 & 0.58 & 187 & 16.22 & 157 & 0.85 \\
\hline Limit Stress**, MPa & 588 & 0.74 & 583 & 5.89 & 464 & 0.49 \\
\hline
\end{tabular}

* $\mathrm{SE}$, the Standard Error, is given by $\mathrm{SE}=\mathrm{SD} / \sqrt{N}$, where $\mathrm{SD}$ is the Standard Deviation and $\mathrm{N}$ is the sample size, as given by the number in parentheses next to the average value of each property for steps 1,2 , and 3

** Maximum strength value reached when the test was interrupted and the specimen was unloaded 
the YS is related to the improvement of the material ductility. For the limit stress, only the values obtained for steps 1 and 2 can be compared (due to the equivalent limit strain applied), since the last (third) step was intentionally stopped at $20 \%$ strain. The same level of limit stress $(\sim 585 \mathrm{MPa})$ was reached in both steps 1 and 2 with a variation of less than $1 \%$.

\subsection{Microstructural Analysis}

3.2.1 Grain Size Distribution. The analysis of the distribution in the austenite grain size, as illustrated in Fig. 4, was performed based on the EBSD maps. It is noteworthy that for this analysis the number of grains sampled for each specimen, as listed in Table 4, should be suitable for a reliable statistical analysis, considering that typically a minimum set of 200 grains and a step size ten times smaller than the grain diameter is recommended. Figure 4 relates the effect of both the deformation and heat treatment on the grain size evolution through an understanding of cumulative grain size distributions. In particular, the two curves left of the "reference" curve of the 'SR' material condition present the effect of deformation. It can be observed that as the applied strain increases, the austenite grain size decreases, as evidenced from the shift of the grain size distribution toward lower grain size values. During deformation, the grains are dislocated and their shape is changing due to local deformation gradients (triple points) and martensite formation. Thus, the microstructure is fragmented as the plastic strain increases and the average grain size decreases. When the SR heat treatment step is introduced, the average grain size increased and the cumulative distribution of the 'SR $+40 \%+$ SR' material condition significantly shifted to larger grain sizes. Specifically, the increase in the grain size observed for the 'SR + 40\% + SR' material condition (having a full cycle of deformation and heat treatment) relative to the 'SR' material can be related to two

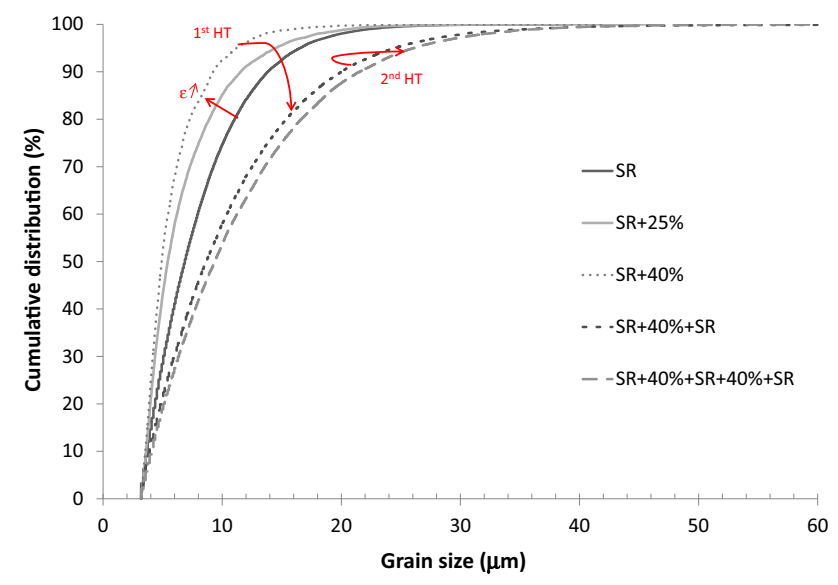

Fig. 4 Cumulative distribution of grain size measured statistically by EBSD on the five specimens: 'SR,' 'SR $+25 \%$,' 'SR $+40 \%$,' 'SR $+40 \%+$ SR,' and 'SR $+40 \%+\mathrm{SR}+40 \%+$ SR' phenomena: a recrystallization and a phase transformation from martensite to austenite. In fact, at the end of the first deformation, step1 (SR $+40 \%$ ), the microstructure is mostly composed of severely deformed small austenite grains and martensite. After the SR heat treatment ( SR $+40 \%+\mathrm{SR})$, a new microstructure is generated with equiaxed austenitic grains, which are larger than the initial grains (SR). The level of deformation introduced (low compared to cold rolling) is known to produce larger grains due to the limited nucleation rate during recrystallization. When a second cycle is added ( $\mathrm{SR}+40 \%+\mathrm{SR}+40 \%+\mathrm{SR}$ versus $\mathrm{SR}+40 \%+\mathrm{SR}$ ), the grain growth is maintained even if it is at a lower rate. The grain size increase from 'SR' to 'SR $+40 \%+\mathrm{SR}$ ' is 3 times greater than the grain growth observed from 'SR $+40 \%+$ SR' to 'SR $+40 \%+\mathrm{SR}+40 \%+$ SR' suggesting a quasi-stationary state of the microstructure once the first cycle is completed.

3.2.2 Distribution of Annealing Twins. The distribution of the annealing twins was studied in order to document the effectiveness of recrystallization during the SR heat treatment. Figure 5 displays the fraction of twins at each stage of the multi-step process on top of the cumulative engineering stressstrain curve and Table 5 details the fraction of twins for each step. Figure 6 shows the austenitic matrix with the distribution of grain boundaries as black lines and $60^{\circ}\langle 111\rangle$ twins as red lines. The amount of annealing twins in the SR sample is $44 \%$ and decreased to about 5\% with deformation (no significant difference was observed between the 25 and $40 \%$ deformation conditions). The SR heat treatment applied at the beginning of the tests generated a large number of twins in the specimen (most likely the maximum). The presence of twins in the matrix usually provides a random texture as each twin changes the orientation of the grain. Specifically, stainless steels generally display weak-to-medium textures due to the slow migration of

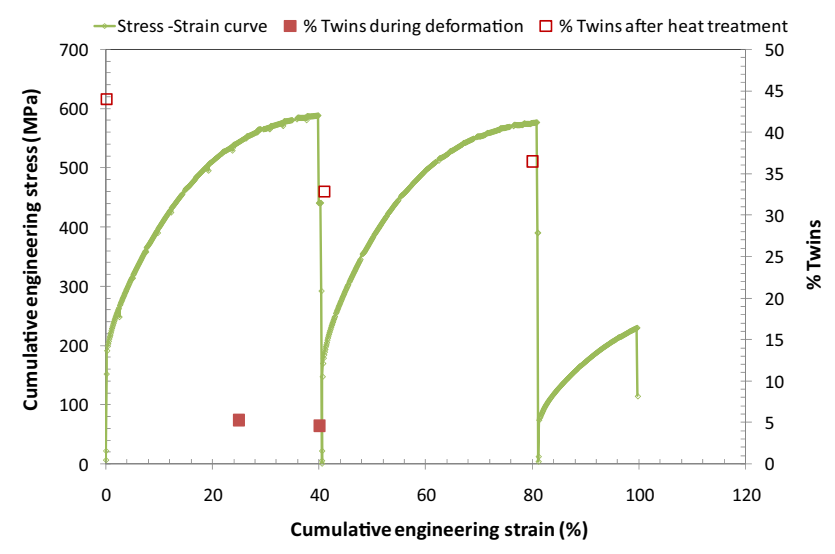

Fig. 5 Fraction of twins superimposed on the average cumulative engineering stress-strain curve acquired through interrupted tensile testing

Table 4 Grain population for statistical analyses of the grain size distribution

\begin{tabular}{llllll}
\hline Specimens & \multicolumn{1}{c}{ SR } & SR + 25\% & SR + 40\% & SR + 40\%+ SR & SR + 40\%+ SR + 40\%+ SR \\
\hline Number of grains & 6670 & 6518 & 4237 & 2150 & 2271 \\
Average grain size* & $9.99 \pm 0.18$ & $4.54 \pm 0.08$ & $2.57 \pm 0.05$ & $8.38 \pm 0.42$ & $11.83 \pm 0.38$ \\
$*$ Standard error with $95 \%$ level of confidence & & & & \\
\hline
\end{tabular}


Table 5 Fraction of twins in specimens subjected to interrupted tensile testing

\begin{tabular}{lccccc}
\hline Specimens & SR & SR + 25\% & SR + 40\% & SR + 40\%+ SR & SR + 40\%+ SR + 40\%+ SR \\
\hline Twin fraction (\%) & 44.0 & 5.3 & 4.6 & 32.9 & 36.5 \\
\hline
\end{tabular}

(a) SR

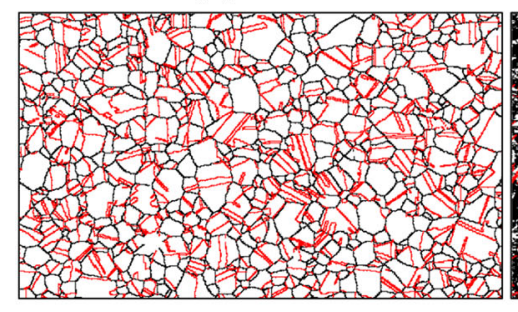

(b) $\mathrm{SR}+25$

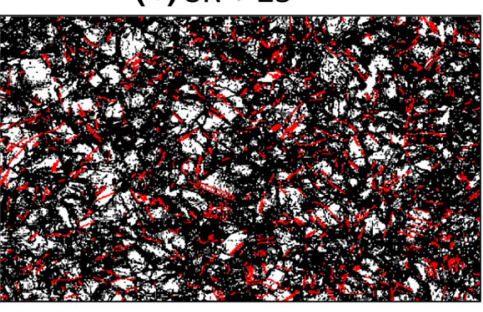

(c) $\mathrm{SR}+40$

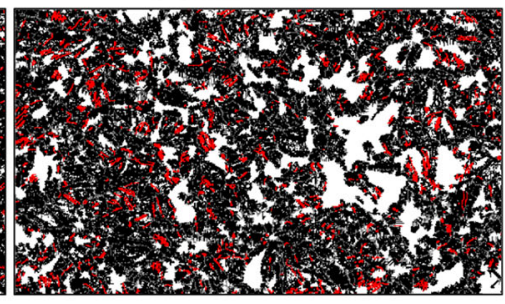

(e) $\mathrm{SR}+40+\mathrm{SR}+40+\mathrm{SR}$
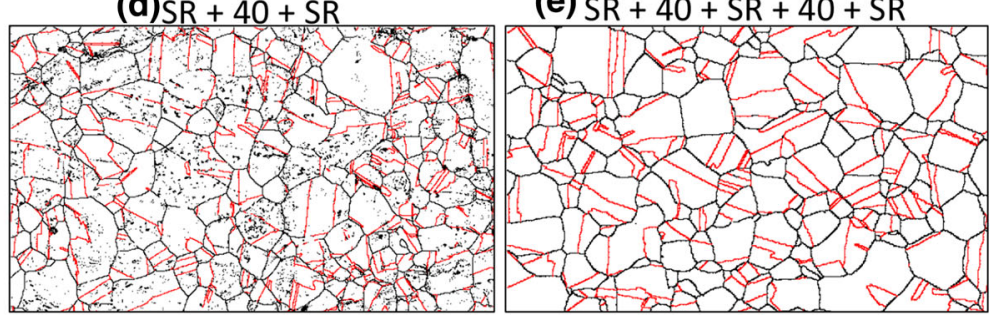

Fig. 6 Austenitic matrix shown with a distribution of grain boundaries (black lines) and annealing twins (red lines): (a) SR, (b) SR $+25 \%$, (c) $\mathrm{SR}+40 \%$, (d) SR $+40 \%+\mathrm{SR}$, and (e) $\mathrm{SR}+40 \%+\mathrm{SR}+40 \%+\mathrm{SR}$ (Color figure online)

the large angle boundaries. This ensures that many orientations are available for plastic deformation and some of these can plastically deform earlier than others. As observed in Fig. 6, when the applied strain is increased, it is increasingly difficult to distinguish twins as well as grains boundaries in the EBSD maps. When the heat treatment was applied, the amount of twins increased from 5\% in the 'SR $+40 \%$ ' condition to $33 \%$ in the 'SR $+40 \%+$ SR' condition, which provides evidence of some major grain boundary displacement. Likewise, when the complete cycle was repeated as in ' $\mathrm{SR}+40 \%+\mathrm{SR}+$ $40 \%+$ SR' condition, the percentage of twins was almost the same as in step 1-SR (36\%). However, the amount of twins following a SR heat treatment after deformation (step 1-SR or 2-SR) remained below that in the starting SR material condition implying that the recrystallization was partial. In other words, the non-recrystallized zones (calculated as the ratio between the percentage of twins after the first and second completed cycles and the starting percentage of twins in the SR condition) was evaluated between 18 and $25 \%$, depending on the number of cycles.

3.2.3 Austenite Texture. Figure 7(a) to (c) show the austenite $\{100\}$ and $\{111\}$ pole figures for the SR material and for the specimens deformed at 25 and $40 \%$ strain. The horizontal direction corresponds to the tensile direction and is parallel to the initial rolling direction (RD). On the pole figures of austenite, a weak $\langle 111\rangle$ and $\langle 100\rangle$ fiber along the tensile direction was found, the $\langle 100\rangle$ fiber being weaker than the $\langle 111\rangle$ one. A maximum MUD (Multiple of Uniform Distribution) of about 2.2 for $\langle 111\rangle$ was found in the RD at $0 \%$ deformation and increased up to about 6 after $40 \%$ strain. The increase of the $\langle 100\rangle / / \mathrm{RD}$ fiber was less significant (from 1.8 to 2.7 respectively). The samples that underwent one
$(\mathrm{SR}+40 \%+\mathrm{SR})$ and two $(\mathrm{SR}+40 \%+\mathrm{SR}+40 \%+\mathrm{SR})$ complete cycles are shown in Fig. 7(d) and (e), respectively. When the heat treatment was applied, the sharpness of both fibers slightly decreased (from 6 to 5.1 in the $\langle 111\rangle$ pole figures and from 2.7 to 2.1 in $\langle 100\rangle$ pole figures).

Another method to represent the texture is the use of Inverse Pole Figures (IPF), as shown in Fig. 8. The intensity in the IPF refers to the MUD associated with a particular crystallographic direction coinciding with a reference direction. The tensile direction (RD) was taken as the reference direction in Fig. 8, as it is a plane of symmetry for the deformation process. Table 6 groups the maximum MUD obtained and the corresponding orientation after specific steps in the multi-step forming process. The effect of deformation in the austenite texture can be seen through Fig. 8(a) to (c). In Fig. 8(a), the starting state (SR) of the material presents a random texture, the MUD being rather very weak (maximum of 2.3). With this representation, the two fibers are clearly seen when increasing the amount of deformation (from 0 to $25 \%$ ), reaching 3.9 and 2.1 for the component $\langle 111\rangle$ and $\langle 001\rangle$, respectively (Fig. 8b). After $40 \%$ strain, in Fig. 8(c), the $\langle 111\rangle$ fiber component is reinforced with a maximum of 5.1 against 2.4 for $\langle 001\rangle$. It is noteworthy that the $\langle 111\rangle$ fiber texture is significantly stronger than the $\langle 101\rangle$ fiber texture. Hence, a considerable portion of the microstructure becomes stabilized due to rotation toward the $\langle 111\rangle$ fiber, while a relatively smaller fraction is represented by the $\langle 101\rangle$ texture.

The effect of the SR heat treatment observed on the pole figures in Fig. 7 is confirmed by the IPF results. The MUD decreases slightly for both fiber directions, displaying some randomization of the texture (Fig. 8c versus d). However, the material remains textured confirming that heat treatment 


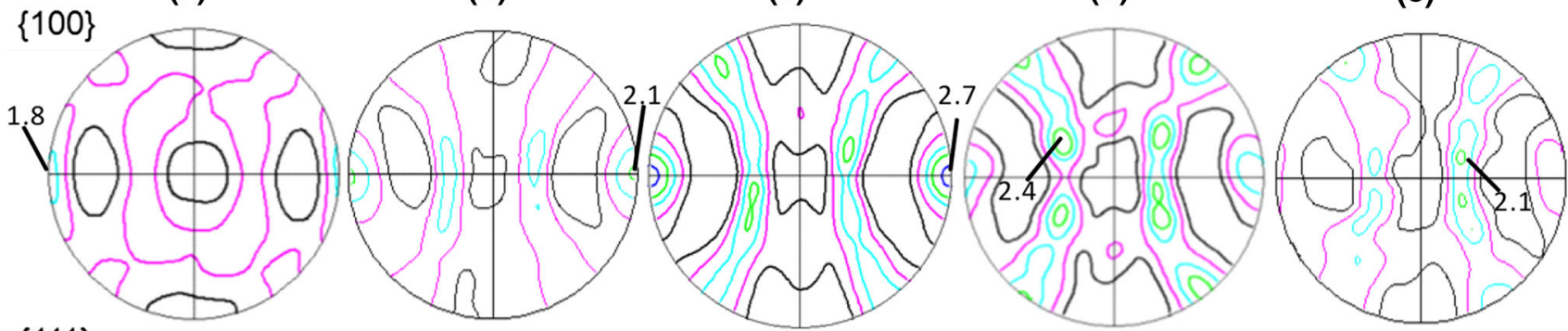

$\{111\}$
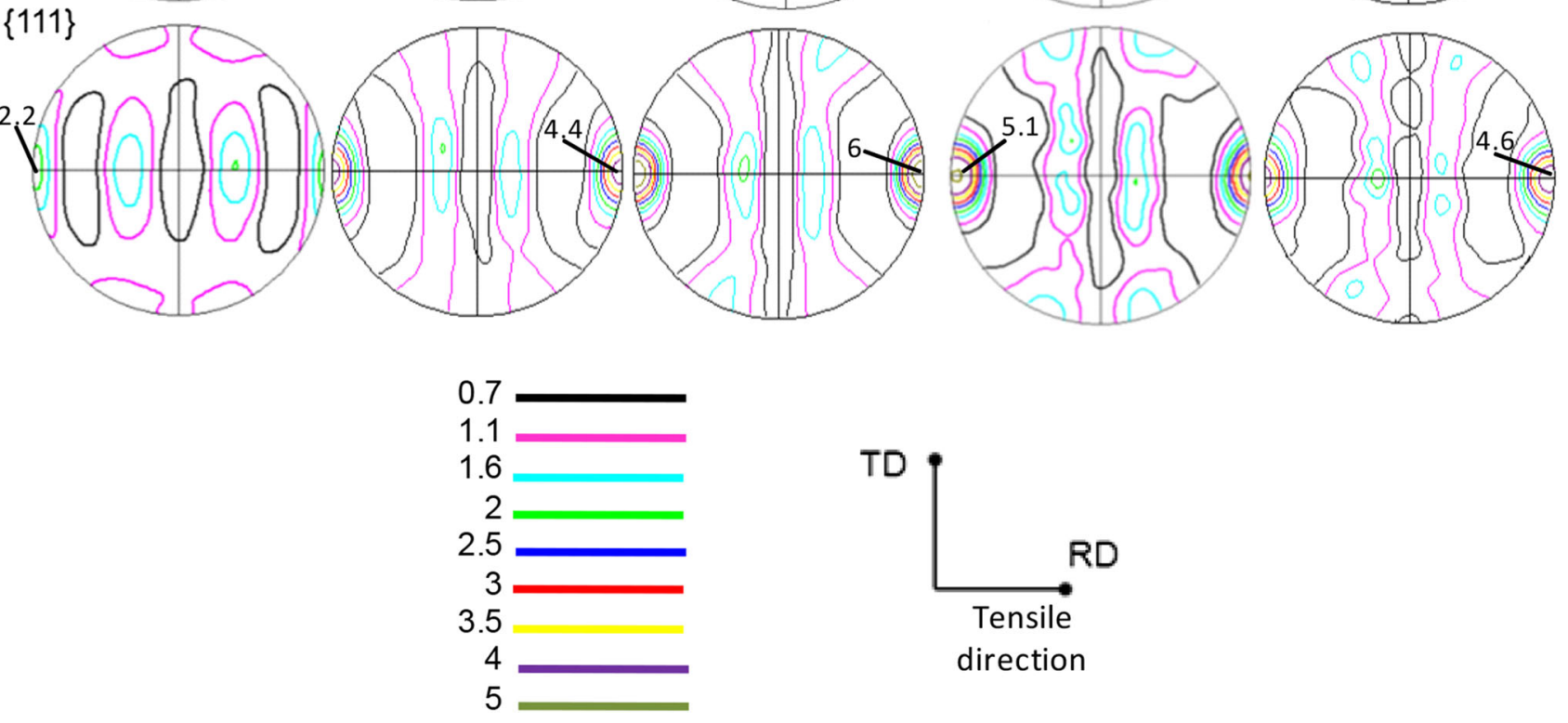

TD

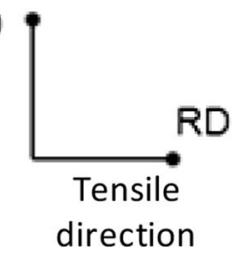

Fig. 7 The $\{100\}$ and $\{111\}$ pole figures of austenite at various stages in the multi-step forming process: (a) SR, (b) SR $+25 \%$, (c) SR $+40 \%$, (d) $\mathrm{SR}+40 \%+\mathrm{SR}$, and (e) $\mathrm{SR}+40 \%+\mathrm{SR}+40 \%+\mathrm{SR}$

(a) SR

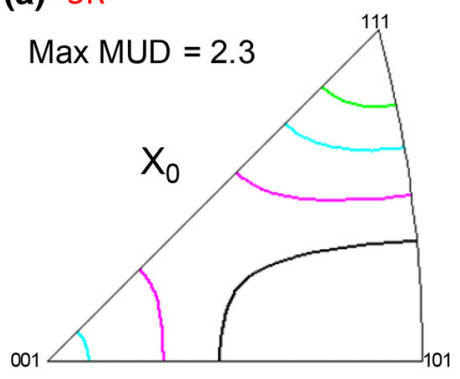

(d) $\mathrm{SR}+40 \%+\mathrm{SR}$

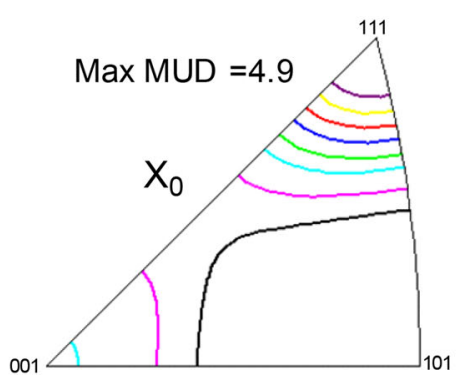

(b) $\mathrm{SR}+25 \%$
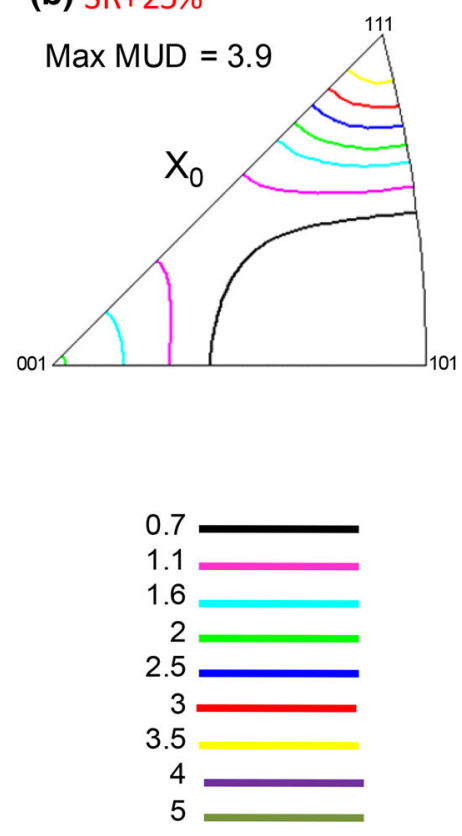

(e) $\mathrm{SR}+40 \%+\mathrm{SR}+40 \%+\mathrm{SR}$

(c) $\mathrm{SR}+40 \%$
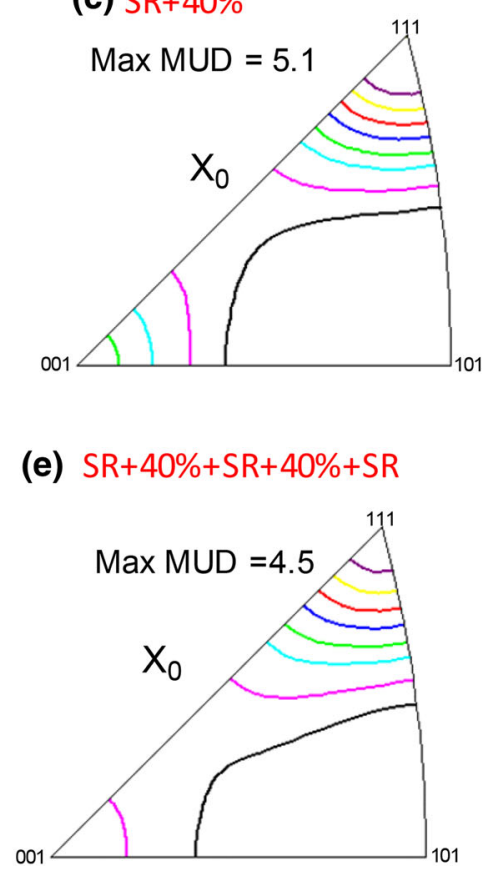

Fig. 8 Rolling and tensile direction inverse pole figures of austenite at various stages in the multi-step forming process: (a) SR, (b) SR $+25 \%$, (c) $\mathrm{SR}+40 \%$, (d) $\mathrm{SR}+40 \%+\mathrm{SR}$, and (e) $\mathrm{SR}+40 \%+\mathrm{SR}+40 \%+\mathrm{SR}$ 
Table 6 Maximum values of MUD and the corresponding orientation of SS 321 after specific steps in the interrupted tensile tests

\begin{tabular}{lcccc}
\hline & \multicolumn{3}{c}{ IPF in RD $\left(\boldsymbol{X}_{\mathbf{o}}\right)$-Austenite } \\
\cline { 2 - 5 } Steps of the process & Orientation & Maximum MUD & Orientation & Maximum MUD \\
\hline $\mathrm{SR}$ & $\langle 111\rangle$ & 2.3 & $\langle 001\rangle$ & 1.8 \\
$\mathrm{SR}+25 \%$ & $\langle 111\rangle$ & 3.9 & $\langle 001\rangle$ & 2.1 \\
$\mathrm{SR}+40 \%$ & $\langle 111\rangle$ & 5.1 & $\langle 001\rangle$ & 2.4 \\
$\mathrm{SR}+40 \%+\mathrm{SR}$ & $\langle 111\rangle$ & 4.9 & $\langle 001\rangle$ & 1.6 \\
$\mathrm{SR}+40 \%+\mathrm{SR}+40 \%+\mathrm{SR}$ & $\langle 111\rangle$ & 4.5 & $\langle 001\rangle$ & 1.0 \\
\hline
\end{tabular}

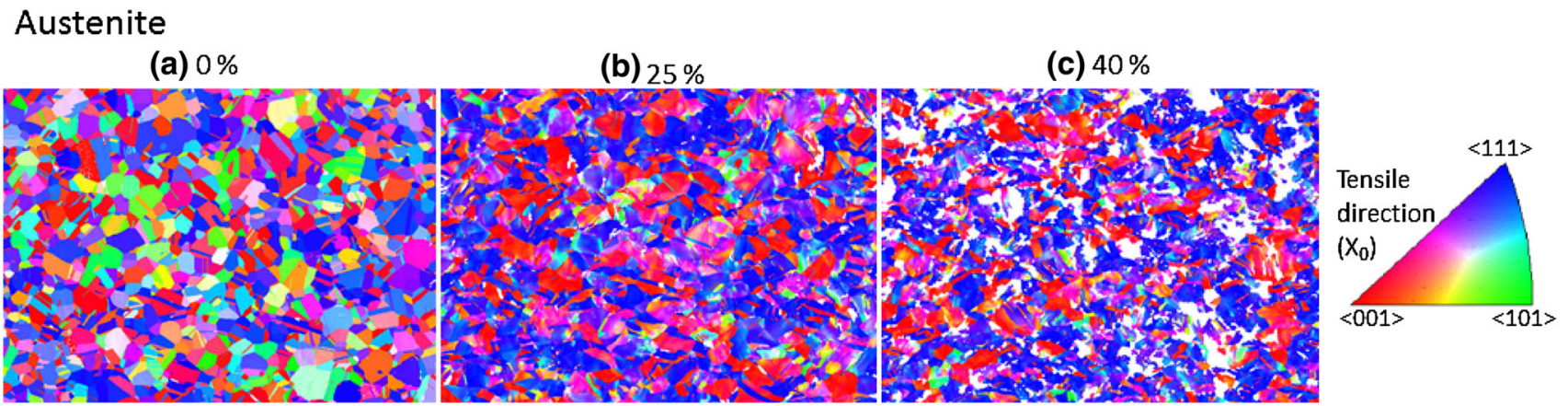

Fig. 9 EBSD orientation maps of austenite (along the RD) in SS 321 at different strain levels

resulted in partial recrystallization. The strongest texture component remains close to the $\langle 111\rangle$ direction and extends from 5.1 to 4.9 , whereas the texture component $\langle 001\rangle$ decreased from 2.4 to 1.6 .

Figure 9 is an illustration of the effect of deformation on the orientation maps. It represents the crystallographic orientation according to the tensile direction for the same area at respectively 0,25 and $40 \%$ deformation for the austenite phase; the reference color code used is shown in the IPF triangle for the tensile direction (initial RD). In this microstructure, the martensite phase (not indexed) is left blank (white). As the strain increased, the $\langle 101\rangle$ texture component (grains demarcated by the green color) decreased and almost disappeared at $40 \%$ strain, whereas the texture component $\langle 111\rangle$ (grains demarcated by the blue color) increased. At the same time, the texture component $\langle 001\rangle$ (grains demarcated by the red color) increased, but not as much as the $\langle 111\rangle$.

\subsection{Strain-Induced Martensite}

Figure 10 shows the $\alpha$-martensite content superimposed on the stress-strain curves. Specifically, the martensite volume fraction is presented as a function of the cumulative engineering strain. The error bars represent the minimum and maximum values measured for the martensite fraction at each strain level. The evolution in the average martensite content is very similar at each step of the multi-step forming process. The martensite amount increases with strain, but its rate of formation remains very low until a specific amount of deformation (around 20\%) is accrued. When this level of strain is reached, the fraction of martensite starts to increase rapidly. The formability limit, in addition to the relative stability of the SS 321 at room temperature, prevents the SIM content from reaching the saturation value, i.e., the maximum amount of martensite that

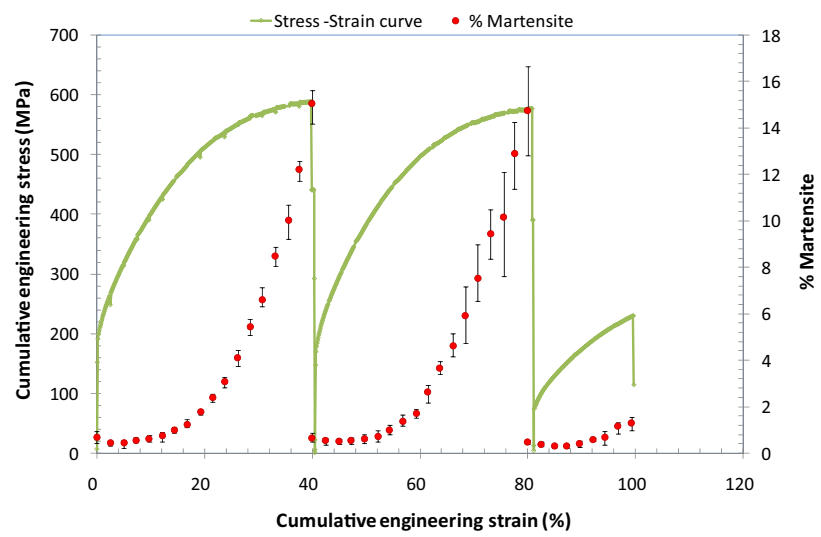

Fig. 10 SIM evolution superimposed on the average cumulative engineering stress-strain curve for specimens subjected to interrupted tensile testing. The error bars represent the minimum and maximum values measured for the martensite content

can be strain induced in the material depends on the chemical composition, temperature, strain rate, and/or austenite grain size. During the second deformation step, large variations in martensite content were recorded (larger error bars). At this point, the gauge length of the specimen had nearly doubled and the martensite content varied significantly from one location to another.

In Fig. 11, the typical evolution in the martensite content with strain distribution is presented for the case of one specimen subjected to multi-step deformation in which steps 2 and 3 were observed to superimpose on the step 1 data. For each step, the SIM formation curve had the general appearance of an initial sigmoidal-shape as it is expected for a SIM distribution but without a saturation phase (at the end) and 


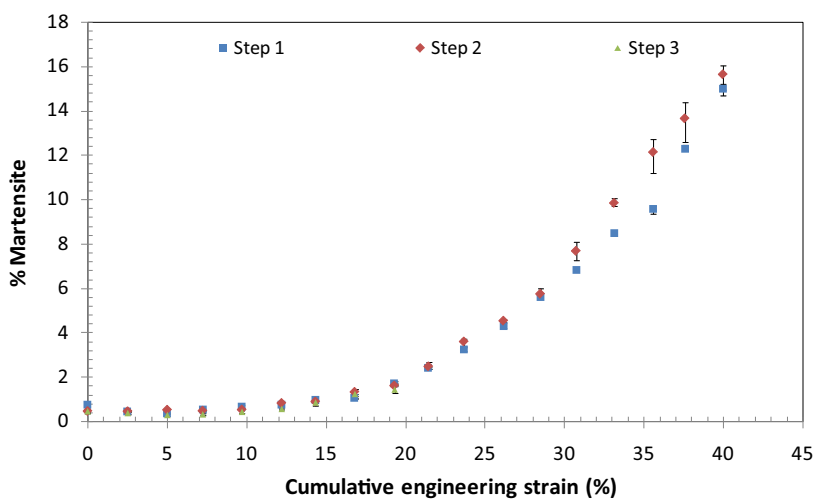

Fig. 11 Typical evolution in the SIM content in one specimen deformed by interrupted tensile testing

could be separated into two parts, as a function of the slope change. For deformations up to $20 \%$ strain, the rate of martensite formation is rather linear, very low, and with no difference observable among the 3 steps. At this point, when the total applied strain exceeds $20 \%$, examining steps 1 and 2 only, the measured fraction of martensite rises sharply and continues to increase with a slope ten times greater than that below 20\% strain. For a given strain value above $20 \%$, the amount of martensite generated was observed to be consistently higher in the second forming step relative to the first. For instance, at a strain of $\sim 35 \%$, the amount of martensite in step 2 was $\sim 20 \%$ higher when compared with that at step 1 and taking into account the standard deviation of the results.

Figure 12 presents the curves obtained after fitting the data with Eq 1 and 2. The Olson-Cohen equation fits very well the experimental data. By contrast, the Tsuta-Grosse equation was unable to capture the trend of the SIM kinetics. In particular, the Tsuta-Grosse equation overestimates the martensite content at the start (early stage) of the deformation and fails to account for the abrupt increase in the rate of formation at around $20 \%$ strain. Hence, the Tsuta-Grosse equation, despite being generated for complex strain paths and low amounts of SIM, was not applicable in the present case. Thus, only the fitting parameters of the Olson-Cohen equation ( $\alpha$ and $\beta$ ) were analyzed further to identify the best fit values for each stage of the multi-step process, as listed in Table 7 . The $\alpha$ parameter is classically related to the rate of shear band formation as a function of the strain (Ref 24, 25). An increase in this parameter from 1.9 to 2.5 between steps 1 and 2 may be indicative of some interesting features related to shear band formation during multi-step forming. Specifically, the combination of deformation and heat treatment seems to facilitate shear band formation that then favors the intersection of shear bands for the nucleation of martensite. The SR heat treatment, despite decreasing the density of dislocations, allows nucleation sites for shear bands to reactivate earlier (at lower stress) in step 2, for instance. It is also possible that some orientations are more favorably oriented for early shear band activation. Research targeted to this understanding is currently ongoing to validate these postulations.

In the Olson-Cohen model, the $\beta$ parameter is proportional to the probability that a shear band intersection will become a martensite nucleation site. From step 1 to step 2 , the $\beta$ parameter is reduced from 4.7 to 2.3 , decreasing the probability of $\alpha$-martensite nucleation from shear band formation. The
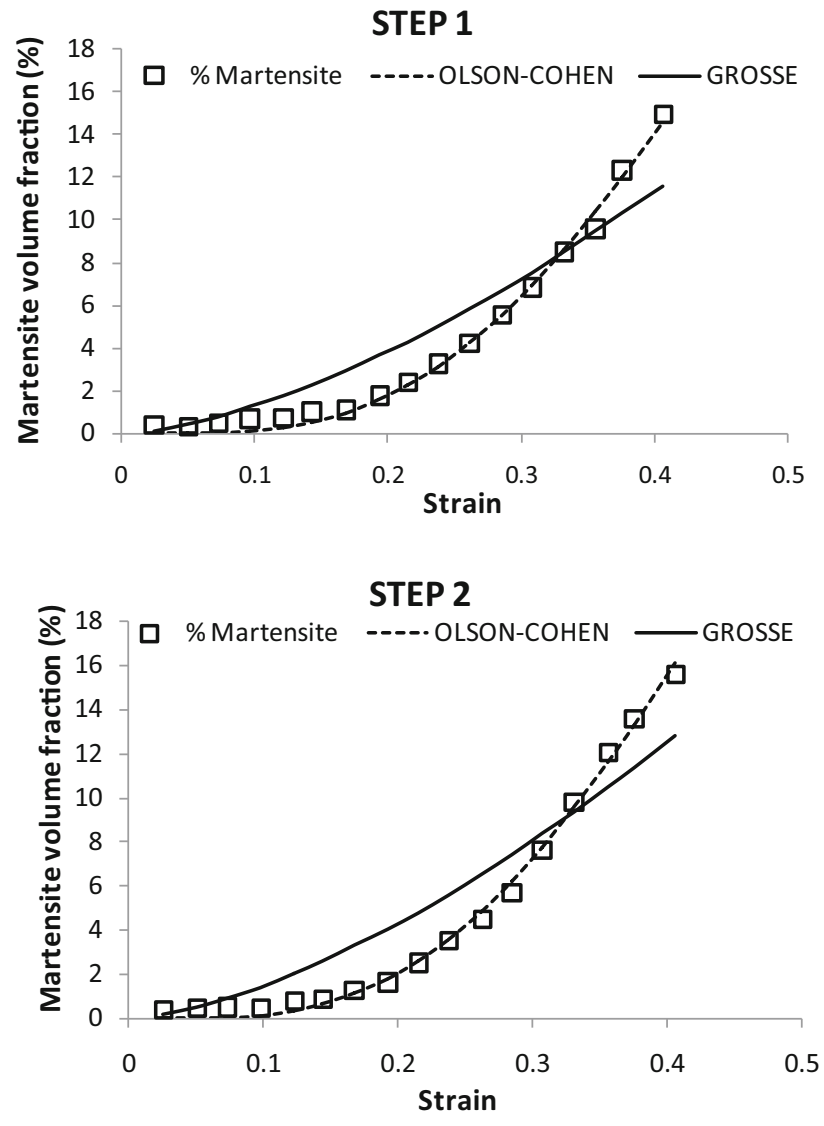

Fig. 12 SIM formation as a function of the cumulative engineering strain in multi-step forming: (a) step1 and (b) step 2

earlier shear bands formed, as suggested by the increase in the $\alpha$ parameter, is therefore balanced by a reduction in the probability of these developing as martensite embryos.

3.3.1 Strain-Induced Martensite Texture. The spatial distribution of the SIM is illustrated in Fig. 13 through orientation maps. In the present case, the austenite phase was left blank and thus appears as white regions in the microstructure. Up to $25 \%$ deformation, the volume fraction of SIM was too low $(3 \%)$ to clearly identify a tendency on the color map, but at $40 \%$ deformation, the amount of martensite $(\sim 15 \%)$ generated was sufficient to describe a $\langle 101\rangle$ texture component (green color). A second texture component was also observed, but to a lower extent, between $\langle 001\rangle$ and $\langle 111\rangle$. Only very few grains were present with an orientation close to $\langle 111\rangle$ according to the RD. In addition, the SIM was well-distributed throughout the microstructure, though some regions appeared almost fully transformed, whereas others had not transformed. These regions may likely be particular grains with specific orientations.

In studying the crystalline texture of the generated SIM, the martensite texture has been treated as BCC crystal structure because it was almost impossible to differentiate with $100 \%$ certainty the $\langle 100\rangle$ and $\langle 001\rangle$ poles using the EBSD method. Figure 14 shows the generated $\alpha^{\prime}$-martensite $\{100\}$ and $\{110\}$ pole figures for the deformed specimens during the first step (to be associated with Fig. 7(b) and (c), respectively). The straininduced martensite formed in the $40 \%$ deformed sample is textured. Also the pole figures display clear evidence of symmetry expected in a rolled and tensile-loaded material. This 
is not as clear in the $25 \%$ deformed specimen, most likely due to the low statistics of measurements as only $3 \%$ of this phase was found at this strain.

In the $40 \%$ strained specimen, the pole figures are symmetrical with the maximum texture residing on the $\langle 100\rangle$ pole with an intensity around 2.6 (Fig. 14). The maximum of the $\langle 110\rangle$ pole figure did not correspond to the maximum found in the

Table 7 Olson-Cohen fitting parameters derived from the $\alpha^{\alpha}$-martensite fraction measured in multi-step forming

\begin{tabular}{lccc}
\hline Olson-Cohen & $\boldsymbol{\alpha}$ & $\boldsymbol{\beta}$ & $\boldsymbol{R}^{\mathbf{2}}$ \\
\hline Deformation step 1 & $1.89 \pm 0.07$ & $4.70 \pm 0.64$ & 0.997 \\
Deformation step 2 & $2.50 \pm 0.26$ & $2.28 \pm 0.76$ & 0.992 \\
\hline
\end{tabular}

$\langle 111\rangle$ austenite pole figure (Fig. 7) as expected from the K-S type relationship, but rather to the second maximum of this $\langle 111\rangle$ pole figure. At the maximum position of the $\langle 111\rangle$ austenite pole figure, a rather low MUD value was found on the martensite $\langle 110\rangle$ pole figure. This maximum position corresponded to the most stable orientations during tensile loading (the $\langle 111\rangle$ fiber along the RD in Fig. 7c). It is unlikely that these orientations undergo SIM transformation during the deformation process. On the other hand, other orientations not initially belonging to $\langle 111\rangle$ fiber may generate SIM to compensate unfavorable slip activity.

The data in Fig. 14 can be translated into an IPF, as presented in Fig. 15. The main pole is around the $\langle 140\rangle$ pole with a MUD around 2 for both specimens showing that the generated SIM remains stable during deformation. (a) $25 \%$

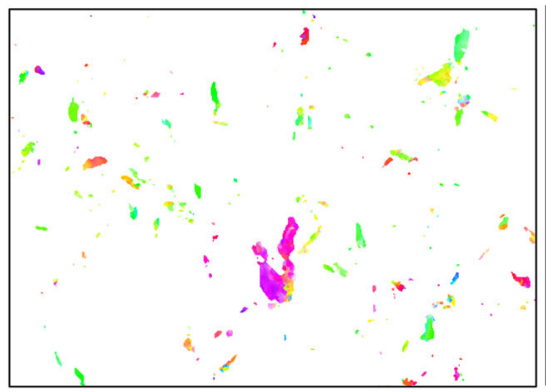

(b) $40 \%$

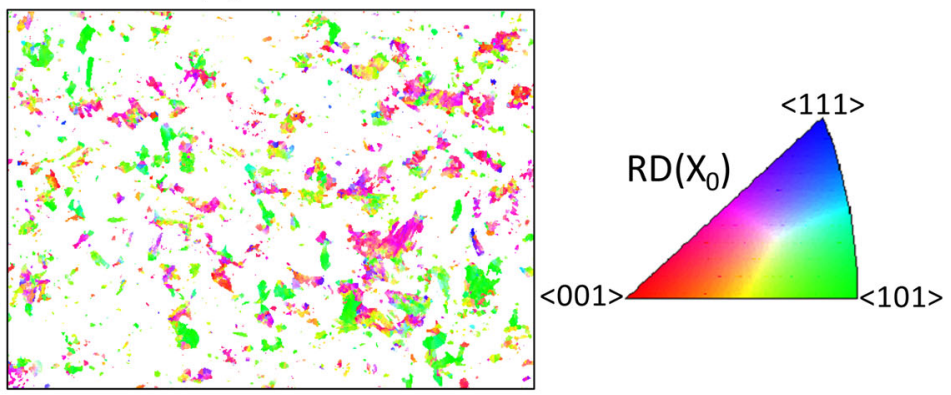

Fig. 13 EBSD orientation maps of martensite (along RD) inSS 321at different strain levels

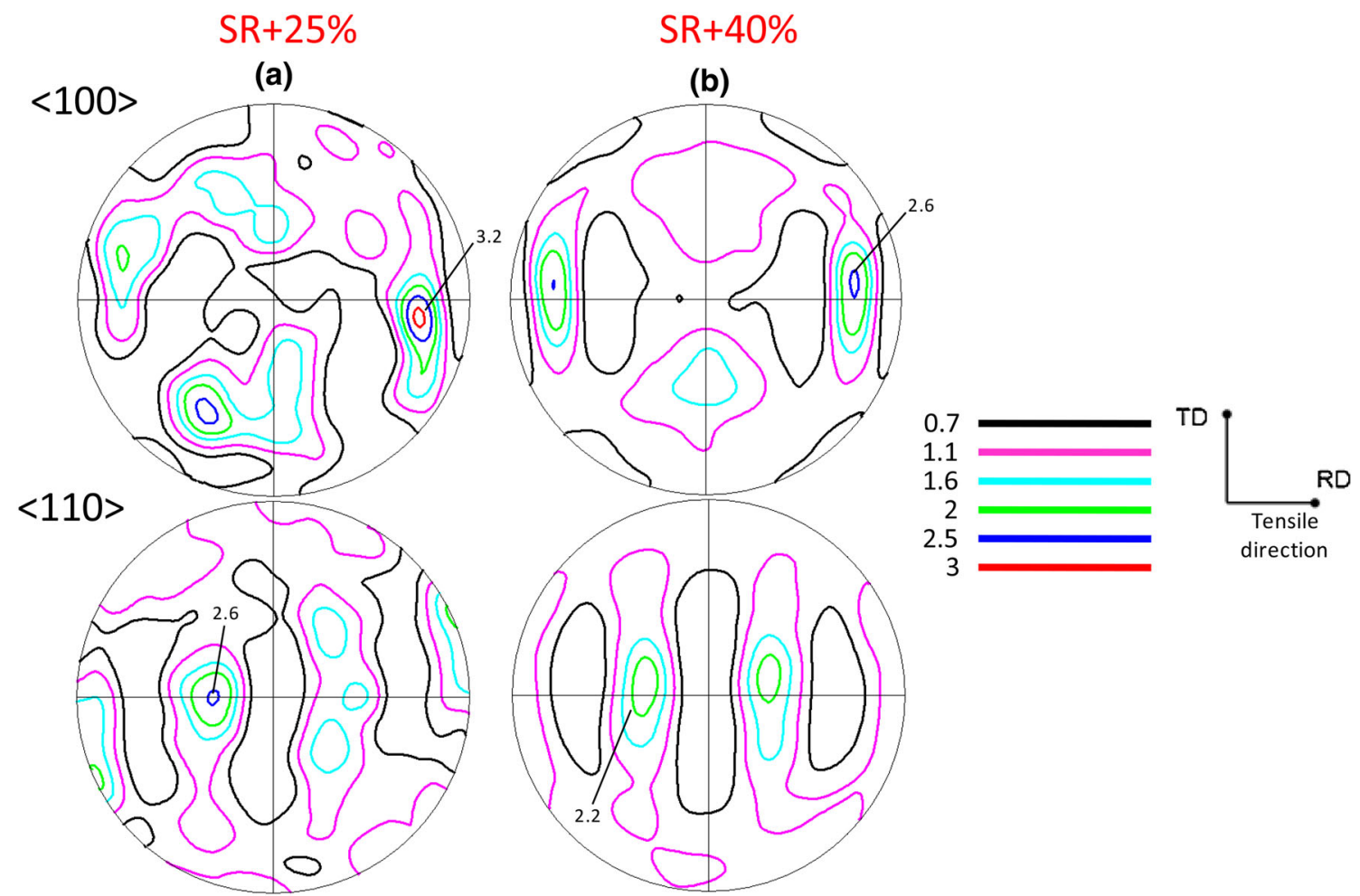

Fig. 14 The $\{100\}$ and $\{110\}$ pole figures for martensite at different strain levels: (a) $\mathrm{SR}+25 \%$ and (b) SR $+40 \%$ 

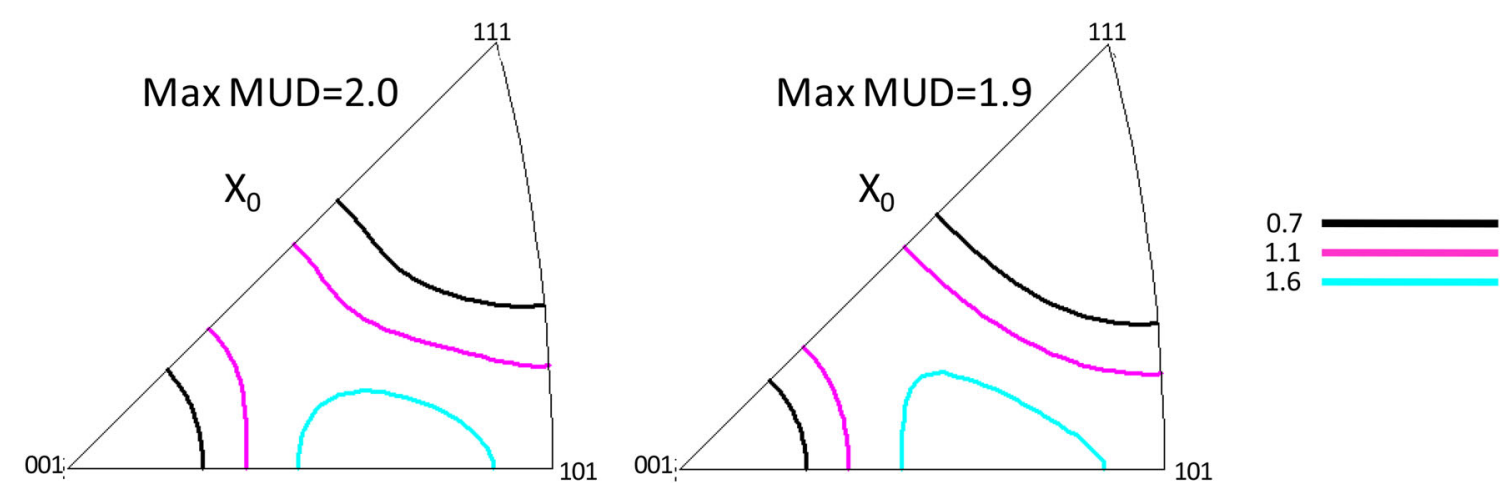

Fig. 15 Rolling and tensile direction inverse pole figures of martensite at different strain levels: (a) SR $+25 \%$ and(b) $\mathrm{SR}+40 \%$

\section{Discussion}

The multi-step forming process applied to SS 321 documented through the experimental results reveals several interesting phenomena. On the macroscopic scale, the intermediate SR heat treatment applied restores very well this material, which gives the possibility of deforming SS 321 up to $100 \%$ strain in 3 steps, and probably higher deformation levels may be reached if additional heat treatment and deformation cycles were to be used. Also the observed decrease in the YS after the SR suggests that the SS 321 is easier to deform with increasing number of deformation-heat treatment cycles. This behavior could be related to some texture evolution. It is important to note that the occurrence of SIM cannot be used to explain the YS variation, as it only influences levels of applied stress greater than the YS. It is most likely related to the small evolution in the texture. The texture development (grains reoriented with respect to the applied deformation) affects the mechanical properties, especially the YS, since it may facilitate or restrict the dislocation motion depending on the activated slip systems. In the present case it contributes to a reduction in the YS by several percentage points.

At the microscopic level, several processes were observed: SIM nucleation and growth during the deformation step, martensite transformation back into austenite during the SR heat treatment together with nucleation and growth in the deformed austenite phase (including the development of many orientations due to the formation of annealing twins). All these processes played a non-negligible role in the material response to the multi-step forming process as discussed below.

\subsection{Strain-Induced Martensite}

A macroscopic indication that the microstructure behaves differently between the first and the second deformation steps can be found in the coefficient of the Olson-Cohen equation. The first parameter, $\alpha$, of this equation describes the rate of shear band formation as a function of the applied strain. The present data suggests that $\alpha$ increased significantly between steps 1 and 2, implying that the shear bands are generated more easily at the second step than in the first. This could be a consequence of the crystalline texture evolution of the starting material (in the SR condition before step 1) and the one at the onset of the second step of deformation. The stronger $\langle 111\rangle$ fiber will favor the early generation of stable shear bands with multiple slips on almost equivalent primary and secondary maximum Schmidt factors $\left(\mathrm{SF}_{2} / \mathrm{SF}_{1} \approx 0.78\right)$. By increasing significantly the number of shear bands during the second deformation step, one could expect to increase considerably the quantity of favorable SIM nucleation sites, as the number of shear band intersections will increase. However, the evolution of the $\beta$ parameter suggests that these intersections are not particularly suitable for martensite generation; specifically, the significant decrease in the value of $\beta$ from step 1 to step 2 suggests that fewer shear band intersections generate $\alpha^{\prime}$ martensite embryos. Also, the results showed that the volume fraction of SIM is systematically higher in the second step for a given strain, indicating that the $\beta$ parameter has less influence on SIM nucleation than the $\alpha$ parameter in the case of multistep forming. However, this has to be experimentally confirmed with micro-scale analyses of deformed samples as in Ref 40 and 41 . In these studies, the grain-scaled deformation processes were tracked through a digital image correlation system combined with EBSD and in situ tensile tests. The results permitted quantification of the strain fields within the grains as well as identifying the onset of deformation. In the case of SIM, this technique will have to be adapted, but it will allow identification of the specific grains and neighborhoods (orientation, texture, Schmidt factor) that are prone to the development of SIM.

\subsection{Recrystallization}

The objective of the intermediate heat treatment was to restore the material in order to allow continued deformation. Both, the level of deformation introduced in the material $(40 \%)$ and the applied temperature and time during the heat treatment were sufficient to induce recrystallization. The enlargement of the grain size distribution after heat treatment suggested that the recrystallization process was ongoing and some grain coarsening had started. The increased presence of annealing twins after heat treatment confirmed the occurrence of recrystallization. However, this amount was always lower than the one measured in a fully recrystallized structure, i.e., the starting material in the SR condition. Annealing twins are formed in FCC materials with low SFE, such as SS 321, during recrystallization. They result from accidents associated with moving grain boundaries, and in particular with recrystallized grains formed from previously deformed material (Ref 5, 42). As the volume fraction of twins measured after the complete deforma- 
tion + heat treatment cycles did not reach the amount expected in a fully recrystallized material, partial recrystallization can be expected in the material. In fact, the percentage of nonrecrystallized zones in the material after the first and second completed cycles was evaluated at 25 and $18 \%$, respectively. The austenite texture analysis brought additional confirmation of the partial recrystallization, as, after a complete 'SR $+40 \%+$ SR' cycle, the material remained with a typical deformation texture. The generation of growth twins induces random textures unless some selective growth occurs during recrystallization (Ref 43, 44). A consequence of the latter would be that the texture of the larger grains would be different from that of the small ones, which was not the case in the present study. The observed randomization of the texture is therefore a consequence of the formation of growth twins and explains the lowering of the MUD intensity in Fig. 8. Likewise, the weak deformation combined with the high solute content in the rolled stainless steels at medium deformation (60-80\%) can explain the presence of weak recrystallization textures in this case. However, this decrease was not enough to erase the deformed material texture.

The SS 321 microstructure developed during the multi-step forming process is quite complex at the end of a complete cycle (at 'SR $+40 \%+$ SR' for instance). Due to partial recrystallization, austenitic grains in a restored state (some dislocation structures were measured in some of the grains after SR, as seen in Fig. 8d) as well as in a recrystallized state, coming from the previous martensite or deformed austenite grains, coexist in the microstructure. Very low values of martensite were measured after one cycle, which implies that $\alpha$ '-martensite does not revert fully to create new austenitic grains. This suggests that the heat treatment temperature is too low to fully bring the material to its thermodynamic stability. Likewise, traces of remnant SIM also add complexity to the microstructure.

\section{Summary and Conclusions}

Objective of this paper was to document the evolution of the mechanical and metallurgical properties of SS 321 during a multi-step forming process that was simulated by a series of tensile tests with an intermediate softening heat treatment. A combination of $40 \%$ strain and stress relief heat treatments was applied to the tensile specimens so as to attain a cumulative strain of $100 \%$. The mechanical properties were fully restored during the two inter-passes in the multi-step forming process by heat treating at $982{ }^{\circ} \mathrm{C}$ for $1 \mathrm{~h}$. This intermediate stress relief heat treatment was observed to decrease the yield strength and enhance the formability. The distribution in the fraction of twins indicated that the intermediate heat treatment led to partial recrystallization of the material at each step. Some grain growth was noted to occur as well. The texture analysis of the austenite showed that by increasing the level of deformation, the material develops a texture with the $\langle 111\rangle$ component tending to align with the loading direction. A second component was found in the $\langle 110\rangle$ fiber. Similar values of MUD were obtained in steps 1 and 2 of the multi-step forming process. The heat treatment applied randomized the deformed austenite texture thus confirming that recrystallization took place and was most likely incomplete.

A texture analysis of the deformed specimens was performed in order to study the impact of the deformation on the strain-induced martensite texture evolution. The strain-induced martensite was generated with a texture that slightly decreased with increasing deformation. The first orientation that formed was near the $\langle 140\rangle$ pole.

The Olson-Cohen equation impeccably fitted the straininduced martensite data in the case of the multi-step forming process examined in this work. The evolution of the $\alpha$ and $\beta$ parameters related to this equation suggests that the multi-step forming process tends to promote shear band formation, but at the same time limits the probability that a shear band intersection becomes a martensite embryo. Such observations should be confirmed with more experimental data and microscale observations.

\section{Acknowledgments}

The authors would like to extend their gratitude to the Natural Sciences and Engineering Research Council of Canada (NSERC), the Consortium for Research and Innovation in Aerospace in Quebec under the CRIAQ 4.6 project and the Fonds de recherche du Québec-Nature et technologies (FRQNT) for their financial support. The authors are also grateful to Mr. Daniel Turner at PWC for his assistance and support for the heat treatments.

\section{References}

1. R.L. Fullman and J.C. Fisher, Formation of Annealing Twins During Grain Growth, J. Appl. Phys., 1951, 22(11), p 1350-1355

2. S. Dash and N. Brown, An Investigation of the Origin and Growth of Annealing Twins, Acta Metall., 1963, 11(9), p 1067-1075

3. H. Gleiter, The Formation of Annealing Twins, Acta Metall., 1969, 17(12), p 1421-1428

4. M.A. Meyers and L.E. Murr, A Model for the Formation of Annealing Twins in F.C.C. Metals and Alloys, Acta Metall., 1978, 26(6), p 951-962

5. J.R. Cahoon, Q. Li, and N.L. Richards, Microstructural and Processing Factors Influencing the Formation of Annealing Twins, Mater. Sci. Eng. A, 2009, 526(1-2), p 56-61

6. P.L. Mangonon, Jr, and G. Thomas, Structure and Properties of Thermal-Mechanically Treated 304 Stainless Steel, Metal. Trans., 1970, 1, p 1587-1594

7. R.A. Lula, J.G. Parr, and A. Hanson, Ed., Stainless Steel, rev ed., American Society for Metals. x, Metals Park, Ohio, 1989, p 173

8. N. Gey, B. Petit, and M. Humbert, Electron Backscattered Diffraction Study of/Martensitic Variants Induced by Plastic Deformation in 304 Stainless Steel, Metall. Mater. Trans. A, 2005, 36, p 3291-3299

9. M. Smaga, F. Walther, and D. Eifler, Deformation-Induced Martensitic Transformation in Metastable Austenitic Steels, Mater. Sci. Eng. A, 2008, 483-484(1-2 C), p 394-397

10. R.B. Kumar et al., Role of Strain-Induced Martensite on Microstructural Evolution During Annealing of Metastable Austenitic Stainless Steel, J. Mater. Sci., 2010, 45, p 911-918

11. T. Angel, Formation of Martensite in Austenitic Stainless Steels, Iron Steel Inst. J., 1954, 177(Part 1), p 165-174

12. S. Hecker et al., Effects of Strain State and Strain Rate on DeformationInduced Transformation in 304 Stainless Steel: Part I. Magnetic Measurements and Mechanical Behavior, Metal. Mater. Trans. A, 1982, 13(4), p 619-626

13. M. Grosse et al., Influencing Parameters on Martensite Transformation During Low Cycle Fatigue for Steel AISI, 321, Mater. Sci. Eng. A, 2006, 437(1), p 109-113

14. X. Chunchun, H. Gang, and W.-Y. Ng, Relationship Between the Martensite Phase Transition and Pitting Susceptibility of AISI-321 Stainless Steel in Acidic Solutions of NaCl, Mater. Sci., 2004, 40(2), p 252-259

15. M.B. Leban and R. Tisu, The Effect of TiN Inclusions and Deformation-Induced Martensite on the Corrosion Properties of AISI, 321 Stainless Steel, Eng. Fail. Anal., 2013, 33, p 430-438 
16. M. Durand-Charre, The Microstructure of Superalloys, Vol xiv, CRC Press, Boca Raton, FL, 1997, p 124

17. G.W. Meetham, The Development of Gas Turbine Materials, Vol xi, Halsted Press, New York, NY, 1981, p 306

18. G. Olson and M. Cohen, A General Mechanism of Martensitic Nucleation: Part I. General Concepts and the FCC $\rightarrow$ HCP Transformation, Metal. Mater. Trans. A, 1976, 7(12), p 1897-1904

19. N. Solomon and I. Solomon, Deformation Induced Martensite in AISI, 316 Stainless Steel, Revista de Metalurgia, 2010, 46(2), p 121-128

20. J. Talonen et al., Effect of Strain Rate on the STRAIN-Induced, \& rarr Martensite Transformation and Mechanical Properties of Austenitic Stainless Steels, Metal. Mater. Trans. A Phys. Metal. Mater. Sci., 2005, 36A(Compendex), p 421-432

21. S. Ghosh, P. Mallick, and P. Chattopadhyay, Effect of Reversion of Strain Induced Martensite on Microstructure and Mechanical Properties in an Austenitic Stainless Steel, J. Mater. Sci., 2011, 46(10), p 3480-3487

22. A. Rosen, R. Jago, and T. Kjer, Tensile Properties of Metastable Stainless Steels, J. Mater. Sci., 1972, 7(8), p 870-876

23. S. Peterson, M. Mataya, and D. Matlock, The Formability of Austenitic Stainless Steels, JOM, 1997, 49(9), p 54-58

24. G.B. Olson and M. Cohen, Kinetics of Strain-Induced Martensitic Nucleation, Metal. Trans. A, 1975, 6(4), p 791-795

25. J.A.C. Ramirez et al., Flow Stress and Phase Transformation Analyses in the Austenitic Stainless Steel under Cold Working: Part 1, Phase Transformation Characteristics and Constitutive Formulation by Energetic Criterion, JSME I. J. Ser. 1 Solid Mech. Strength Mater., 1992 , 35(2), p 201-209

26. T. Tsuta and J. Cortes RA, Flow Stress and Phase Transformation Analyses in Austenitic Stainless Steel Under Cold Working: Part 2, Incremental Theory Under Multiaxial Stress State by the Finite-Element Method, JSME Int. J. Ser. A Mech. Mater. Eng., 1993, 36(1), p 63-72

27. J.A. Venables, The Martensite Transformation in Stainless Steel, Phil. Mag., 1962, 7(73), p 35-44

28. R.K. Ray et al., Transformation Textures in Steels, ISIJ Int., 1994, 34(12), p 927-942

29. A. Kurc-Lisiecka, W. Ozgowicz, and W. Ratuszek, Development of Deformation Texture of Austenitic Cr-Ni Steel, Mach. Technol. Mater. Virtual J., 2012, 9, p 47-50

30. G. Kurdjumow and G. Sachs, Über den Mechanismus der Stahlhärtung, Zeitschrift für Physik, 1930, 64(5-6), p 325-343
31. B.R. Kumar et al., Deformation-Induced Transformation Textures in Metastable Austenitic Stainless Steel, Mater. Sci. Eng. A, 2006, 429(12), p 205-211

32. J.A. Jiménez and G. Frommeyer, Analysis of the Microstructure Evolution During Tensile Testing at Room Temperature of HighManganese Austenitic Steel, Mater. Charact., 2010, 61(2), p 221-226

33. D. Barbier et al., Analysis of the Tensile Behavior of a TWIP Steel Based on the Texture and Microstructure Evolutions, Mater. Sci. Eng. A, 2009, 500(1-2), p 196-206

34. H. Chandler, Ed., Heat Treater's Guide: Practices and Procedures for Irons and Steels, Vol vii, 2nd ed., ASM International, Materials Park, $\mathrm{OH}, 1995$, p 903

35. M. Anderson, Improving the Formability of Stainless Steel 321 Through Multi-step Deformation for Hydroforming Applications, Trans. Can. Soc. Mech. Eng., 2013, 37(1), p 39

36. Fischer, Operator's manual for Feritscope MP30E-S. 2006

37. A.M. Beese, D. Mohr, Experimental Quantification of Phase Transformation in Austenitic Stainless Steel, SEM 2009 Annual Conference \& Exposition on Experimental \& Applied Mechanics, Society for Experimental Mechanics, Albuquerque, New Mexico, 2009

38. J. Talonen, P. Aspegren, and H. Hänninen, Comparison of Different Methods for Measuring Strain Induced $\alpha$-Martensite Content in Austenitic Steels, Mater. Sci. Technol., 2004, 20(12), p 1506-1512

39. M. Anderson et al., Formability Extension of Aerospace Alloys for Tube Hydroforming Applications, Int. J. Mater. Form., 2010, 3(SUPPL 1), p 303-306

40. F. Bridier et al., Microscopic Strain and Crystal Rotation Measurement Within Metallurgical Grains, Key Eng. Mater, 2014, 592-593, p 493496

41. J.C. Stinville et al., High Resolution Mapping of Strain Localization Near Twin Boundaries in a Nickel-Based Superalloy, Acta Mater., 2015, 98, p 29-42

42. K.H. Song, Y.B. Chun, and S.K. Hwang, Direct Observation of Annealing Twin Formation in a Pb-Base Alloy, Mater. Sci. Eng. A, 2007, 454-455, p 629-636

43. G. Gottstein, Annealing Texture Development by Multiple Twinning in f.c.c. Crystals, Acta Metall., 1984, 32(7), p 1117-1138

44. A.A. Saleh, E.V. Pereloma, and A.A. Gazder, Texture Evolution of Cold Rolled and Annealed Fe-24Mn-3Al-2Si-1Ni-0.06C TWIP Steel, Mater. Sci. Eng. A, 2011, 528(13-14), p 4537-4549 